УДК 339.5(571.54:517.3)

https://doi.org/10.24866/1813-3274/2020-3/35-43

В. О. Намжилова ${ }^{1}$, Бурятский научный центр СО РАН, г. Улан-У дэ, Россия E-mail: dayavika@yandex.ru

\title{
РЕСПУБЛИКА БУРЯТИЯ В РОССИЙСКО-МОНГОЛЬСКОЙ ТОРГОВЛЕ
}

Аннотация. В статье представлен анализ динамики внешнеторговых связей Республики Бурятия с Монголией за последнее десятилетие. Рассмотрено как участие региона в формировании российско-монгольского товарооборота, так и место Монголии во внешнеторговых связях республики. В товарной структуре региональной торговли с Монголией обозначен тренд расширения номенклатуры экспорта и импорта, главным образом за счёт продуктов питания. Отмечается вовлечение во внешнеторговые связи малого и среднего бизнеса при поддержке региональных властей. Отдельно рассмотрена транспортно-логистическая среда в Республике Бурятия, где консолидируется значительная часть следующих в Монголию грузов со всех российских регионов.

Ключевые слова: российско-монгольская торговля, Республика Бурятия, Монголия, экспорт продуктов питания; развитие деловых связей, автомобильные и железнодорожные грузоперевозки.

Victoria O. Namzhilova ${ }^{2}$, Buryat Scientific Centre of SB RAS, Ulan-Ude, Russia E-mail: dayavika@yandex.ru

Abstract. The article presents the analysis of the dynamics of foreign trade relations between the Republic of Buryatia and Mongolia over the past decade. Both the participation of the region in the formation of the Russian-Mongolian trade turnover

\footnotetext{
${ }^{1}$ Виктория Очировна Намжилова, кандидат экономических наук, научный сотрудник, Бурятский научный центр СО РАН, г. Улан-Удэ, Россия.

Для цุитирования: Намжилова В. О. Республика Бурятия в российско-монгольской торговле // Азиатско-Тихоокеанский регион: экономика, политика, право. 2020. №. 4. С. 35-43. DOI https://doi.org/10.24866/1813-3274/2020-3/35-43.

${ }^{2}$ Victoria O. Namzhilova, Candidate of Sciences in Economics, Research Fellow, Buryat Scientific Centre of SB RAS, Ulan-Ude, Russia.

For citing: Namzhilova V. O. Republic of Buryatia in Russian-Mongolian trade // PACIFIC RIM: Economics, Politics, Law. 2020. N. 4. P. 35-43. DOI https://doi.org/10.24866/1813-3274/2020-3/35-43.
}

(C) Намжилова В. О., 2020 
and the place of Mongolia in the republic's foreign trade relations have been reviewed. In the commodity structure of regional trade with Mongolia, there is a trend towards expanding the range of exports and imports, mainly due to food products. Involvement of small and medium-sized businesses in foreign trade with the support of regional authorities is noted. The transport and logistics environment in the Republic of Buryatia is considered separately; a significant part of cargoes arriving from all Russian regions is consolidated here.

Keywords: Russian-Mongolian trade, the Republic of Buryatia, Mongolia, export of food products, development of business ties, road and rail freight.

Долгое время в силу разных причин вопросы торгово-экономического сотрудничества России и Монголии оставались второстепенными. Эксперты признают, что многолетнюю историю добрососедских отношений необходимо укреплять экономически [1]. В этом ключе автор ставит задачу оценить участие приграничного с Монголией региона - Республики Бурятия - в российскомонгольской торговле, а также рассмотреть особенности и проблемы осуществления грузоперевозок через границу.

Республика Бурятия была одним из немногих российских регионов, с которыми Монголия поддерживала внешнеэкономические связи после резкого спада взаимной торговли в начале 1990-х гг., тогда экономические взаимоотношения между Россией и Монголией сместились в приграничье [2]. В последние же годы наблюдается снижение степени участия республики в российско-монгольской торговле. На сегодняшний день вклад региона в российско-монгольский товарооборот крайне мал: за 2011-2019 гг. он снизился с 3,9 до 2,1\% (рис. 1).

Монголия традиционно считалась одним из основных партнёров региона в 2000-е гг. - монгольское направление обеспечивало не менее 10\% внешнеторгового оборота Республики Бурятия. Так, в 2000 г. этот показатель составлял 13,1\%, в 2005 г. - 15,2\%. При этом объём торговли рос неизменно вплоть до 2011 г. Значительное снижение товарооборота отмечается в период 2011-2015 гг., когда удельный вес Монголии в общем объёме внешней торговли Республики Бурятия снизился с 6,7 до рекордно низких 2\%. Такой резкий спад удельного веса объясняется сокращением экспорта в Монголию при существенном росте экспорта в другие страны. Три следующих года отмечалось оживление, но оно не позволило превзойти уровень 2011 г. (табл. 1). По итогам 2019 г. экспорт региона в Монголию составил 36,7 млн долл., импорт - 2,4 млн долл.

Интересно влияние фактора приграничности на товарную структуру внешнеторгового оборота Республики Бурятия с Монголией, в частности её экспортной составляющей. Если в целом региональный товарооборот с другими зарубежными 
странами формируется в основном за счёт поставок вертолётов, полезных ископаемых, древесины и продукции промежуточного производственного цикла, то для монгольского направления характерна наиболее широкая номенклатура экспортных товаров. При этом тенденция её расширения сформировалась за последние годы: если в 2011 г. Республика Бурятия экспортировала товары в Монголию всего по 24 товарным группам из 97, то в 2019 г. вывозимые туда товары охватывали уже 83 товарные группы общепринятой товарной номенклатуры внешнеэкономической деятельности.

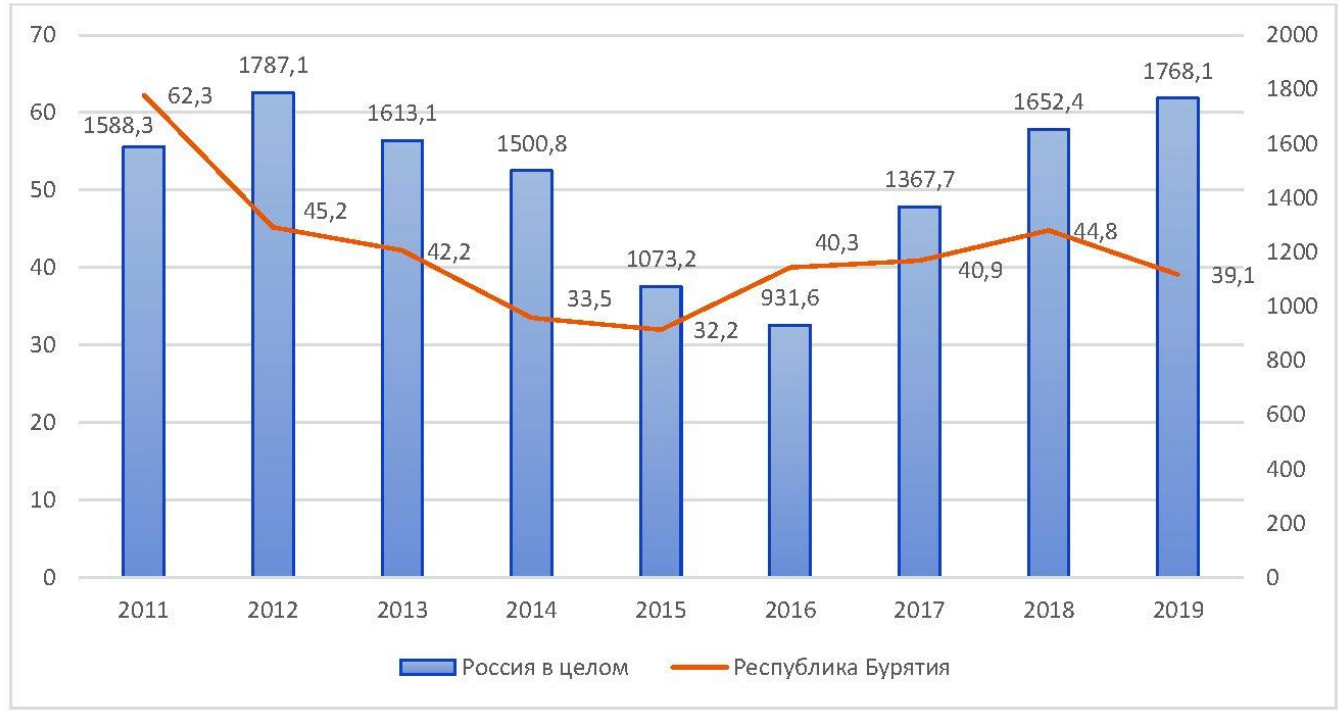

Puc. 1. Динамика внешнеторгового оборота Республики Бурятия с Монголией (левая шкала) на фоне российско-монгольской торговли (правая шкала), млн долл. Источник: статистические данные Федеральной таможенной службы РФ.

URL: http://customs.ru/statistic

Широкая номенклатура экспортных товаров выигрышно выделяет Республику Бурятия в разрезе российских регионов, ведущих торговлю с Монголией, хотя по объёмам экспорта регион значительно уступает Самарской области (774,6 млн долл.), Кемеровской области (251,5 млн долл.), городу Москва (139,4 млн долл.), Иркутской области (70,4 млн долл.), Республике Татарстан (43,0 млн долл.) и городу Санкт-Петербург (42,1 млн долл.) [3]. По данным Российского экспортного центра, Республика Бурятия находится на пятом месте по объёму несырьевого неэнергетического экспорта в Монголию среди российских регионов, при этом, как уже отмечено, номенклатура экспорта отличается наибольшим разнообразием товаров. 
$\frac{\sqrt{2}}{\sqrt{0}}$

\begin{tabular}{|c|c|c|c|c|c|c|c|c|c|}
\hline$\frac{a}{\tilde{d}}$ & $\begin{array}{l}0 \\
\dot{0} \\
0\end{array}$ & $\vec{m}$ & ले & ฉ̊ & हि & $\stackrel{0}{\forall}$ & $\ddot{2}$ & $\stackrel{+}{i}$ & $\tilde{v}$ \\
\hline$\frac{\infty}{\tilde{\sigma}}$ & $\stackrel{\tilde{n}}{\tilde{O}}$ & $\begin{array}{l}\infty \\
f^{\prime}\end{array}$ & $\tilde{\gamma}$ & $\begin{array}{l}0 \\
\stackrel{2}{2} \\
\swarrow 2\end{array}$ & $\begin{array}{l}n \\
0 \\
0 \\
0\end{array}$ & $\begin{array}{l}\infty \\
\dot{m}^{-}\end{array}$ & 总 & 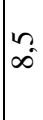 & $\vec{\infty}$ \\
\hline
\end{tabular}

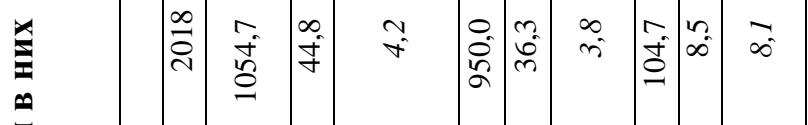

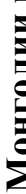

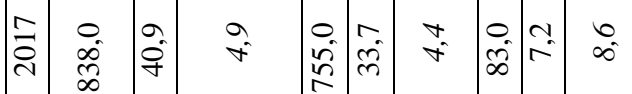

:

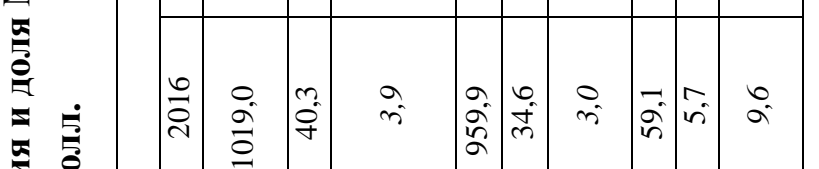

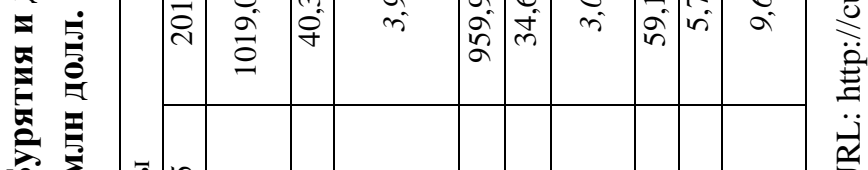

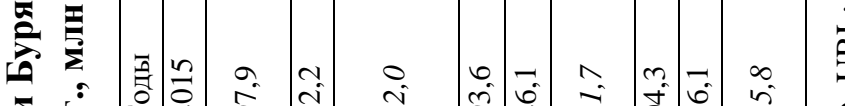

它

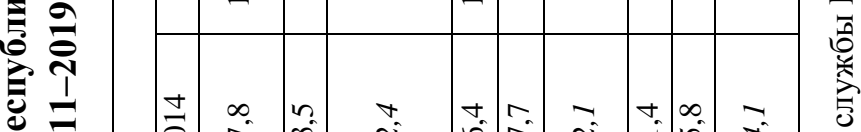

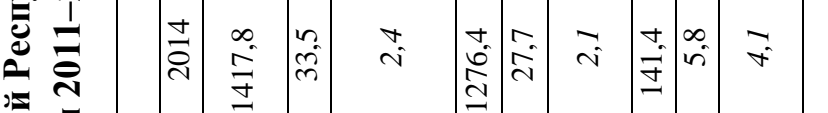

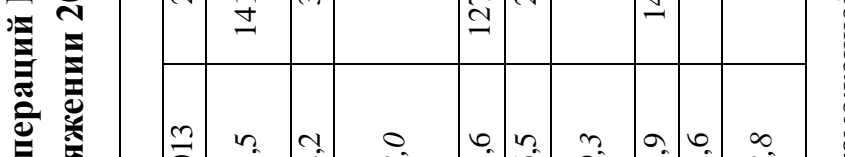

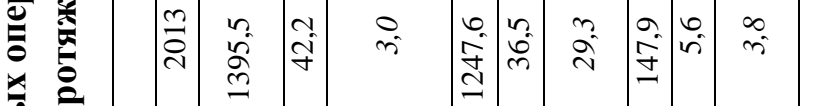

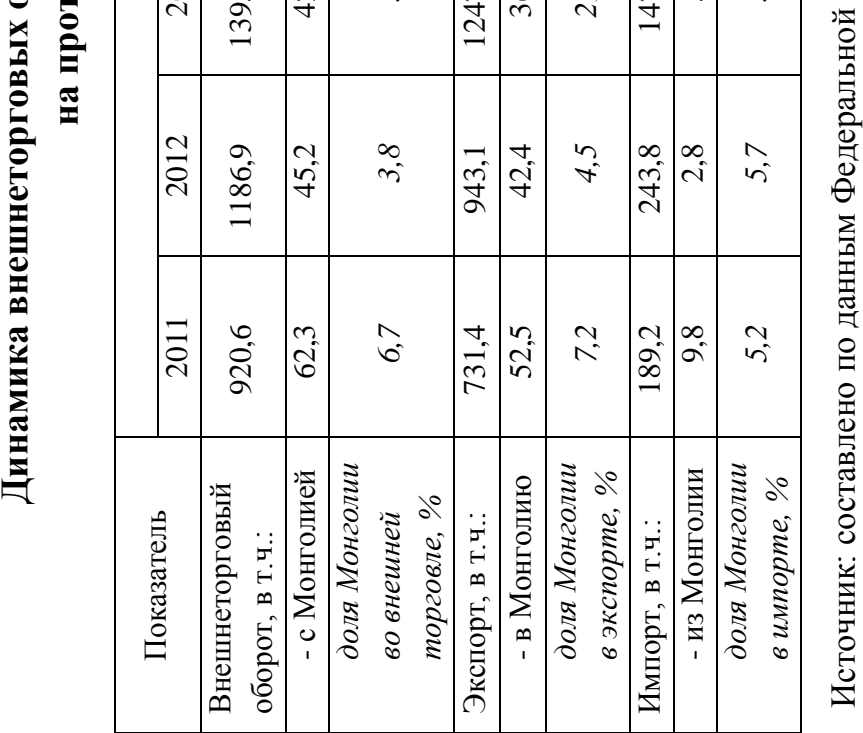


В товарной структуре экспорта Республики Бурятия в Монголию отмечается высокая доля продуктов питания - на них приходится почти половина стоимости вывозимых товаров (46\%). В 2019 г. поставки продовольствия превысили 17 млн долл., где наиболее выделяется экспорт яиц (4,3 млн долл.), а также жиров и масел (2,4 млн долл.). Высоки ожидания по поставкам в Монголию свинины производства свинокомплекса «Восточно-Сибирский», пока единственного поставщика российской свинины на монгольский рынок. В 2018 г. всего на экспорт ушло 490 т свинины, в 2019 г. - 848 т, в планах - увеличение поставок до 200 т в месяц [4]. Также растут поставки шоколадных изделий, экспорт которых превышает 1 млн долл. Поставка продуктов питания на монгольский рынок обладает неплохими перспективами, учитывая, что российские продукты традиционно пользуются популярностью в Монголии. Следует отметить, что экспорт продуктов питания из Республики Бурятия почти полностью ориентирован на Монголию, и взаимодействие бизнес-структур в этом направлении представляет дополнительный канал интенсификации межрегионального сотрудничества [5].

В 2019 г. импорт монгольских товаров в Республику Бурятия составил 2,4 млн долл. Товарная структура импорта значительно скромнее структуры экспорта, в ней на протяжении нескольких лет выделяются два направления: текстиль и продукты питания. В импорте из Монголии также прослеживается тенденция расширения номенклатуры товаров: если в 2011 г. были представлены лишь 10 товарных групп, то в 2019 г. -24.

Как отмечают эксперты, есть все возможности как для диверсификации российского экспорта за счёт продукции с высокой добавленной стоимостью, так и для наращивания импорта из Монголии. В целом, динамика и характер развития межгосударственных отношений становятся благоприятным фоном для позитивных подвижек в приграничном взаимодействии [6]. В последние годы мы наблюдаем активизацию деловых связей, включая участие представительных монгольских делегаций в Восточном экономическом форуме, создание Российско-монгольской рабочей группы по промышленности. Вместе они направлены на создание благоприятных условий для реализации совместных российско-монгольских проектов и выявление новых перспективных направлений сотрудничества, представляющих интерес для обеих сторон. Реализуются или находятся в стадии проработки совместные проекты в таких сферах, как авиационная промышленность, сельскохозяйственное и энергетическое машиностроение, автомобилестроение, металлургия, химическая промышленность, фармацевтика. Дальний Восток, к которому Республика Бурятия отнесена совместно с Забайкальским краем в конце 2018 г., ставит амбициозную задачу увеличения товарооборота с Монголией до полумиллиарда долларов [7].

В этих условиях региональные власти и бизнес проявляют большой интерес к сотрудничеству с Монголией, обозначая главным приоритетом выстраивание долгосрочного сотрудничества между малым и средним бизнесом. Для этих целей реализуется це- 
лый ряд мероприятий, включая проведение в г. Улан-Батор бизнес-конференции «Инвестиционный потенциал Республики Бурятия» (январь 2018 г.), бизнес-конференции в г. Улан-Удэ «Республика Бурятия - Монголия» с участием представителей более ста монгольских компаний (май 2018 г.). Важно, чтобы подобный формат взаимодействия имел своё продолжение и развитие. Решения требует целый комплекс сложных и многоплановых задач: анализ конкурентоспособности республиканских товаров в Монголии, формирование системы поддержки и продвижение местных товаропроизводителей, поиск инвестиционных возможностей для реализации совместных проектов.

Помимо участия Республики Бурятия в российско-монгольской торговле необходимо рассмотреть положение дел в транспортно-логистической сфере региона, поскольку большая часть товарных потоков между Россией и Монголией проходит через расположенные здесь многосторонний автомобильный пункт пропуска Кяхта и железнодорожный пункт пропуска Наушки. Данные таможенной статистики свидетельствуют об устойчивом росте грузоперевозок через (рис. 2), при этом грузопоток в сторону Монголии значительно превышает грузопоток в обратном направлении: на железнодорожном транспорте - в 7,4 раза, на автомобильном - в 13 раз.

На территории Республики Бурятия происходит консолидация значительной части следующих в Монголию грузов со всей России, прежде всего, перевозимых грузовыми автомобилями. Хотя в настоящее время объёмы автомобильных грузоперевозок относительно небольшие, тем не менее наблюдается тенденция к их увеличению вслед за возрастающим взаимным товарооборотом между Россией и Монголией. Потенциальная интенсификация грузовых автомобильных перевозок требует развития транспортно-логистической инфраструктуры в г. Улан-Удэ, а также в местах, приближенных к государственной границе. Так, в ожидании реализации находится проект строительства таможенно-логистического комплекса в непосредственной близости от МАПП Кяхта [8].

Железнодорожные перевозки консолидированных грузов из Республики Бурятия в Монголию значительно уступают по привлекательности автомобильному транспорту по целому ряду причин: высокая стоимость отправки груза (в два раза и более - крытыми вагонами, ещё дороже - контейнерами), увеличенные сроки доставки, дополнительные расходы на перевалку грузов и складирование, особенности оформления таможенных документов.

Однако на фоне вводимых ограничений в секторе автомобильных перевозок, инициированных Монголией во избежание распространения новой коронавирусной инфекции, возник вынужденный интерес к железнодорожным грузоперевозкам. Приостановка работы большей части автомобильных пунктов пропусков на российско-монгольской границе с 16 ноября 2020 г., включая МАПП Кяхта, привело к скоплению грузов на складах перевозчиков и перемещению грузовых потоков на железную дорогу [9]. В этой ситуации стала наглядной необходимость строитель- 
ства современного терминала для обработки железнодорожных грузов. Хотя вопрос создания подобного терминала, к примеру транспортно-логистического центра на базе грузового двора станции Тальцы, обсуждается давно, нынешние условия могут стать катализатором для его решения.

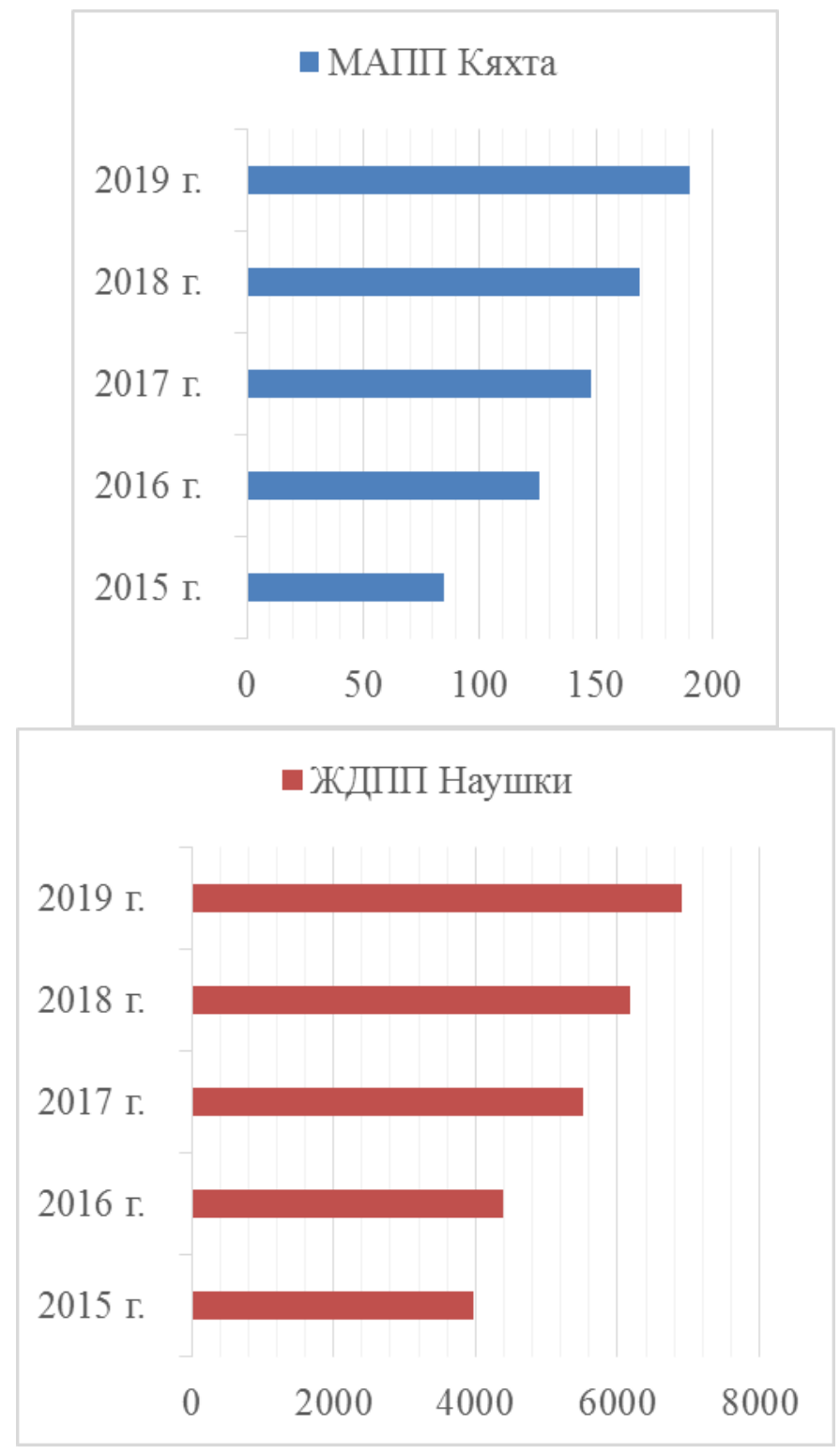

Puc. 2. Динамика грузопотоков в основных пунктах пропуска на российско-монгольской границе (тыс. тонн)

Источник: ведомственные данные Бурятской таможни Дальневосточного таможенного управления за 2015-2019 гг. 
Строительство грузовых терминалов в Республике Бурятия актуально еще и потому, что в целом согласуется с идеей создания комфортных условий для функционирования транспортных коридоров, в том числе в рамках экономического коридора Китай - Монголия - Россия. Как мы видим, в последние годы в международных контейнерных грузоперевозках между Китаем и Европой растет значимость ЖДПП Наушки, который представляет альтернативу маршрутам через пункты пропуска Казахстана и через погранпереход Забайкальск - Маньчжурия. Создание условий для эффективного консолидирования контейнерных грузов в приграничном с Монголией регионе позволит привлечь внимание многих российских грузоотправителей.

Представляется, что грузовая база в направлении Монголии будет также расширяться за счёт местных предприятий, осваивающих монгольский рынок. Развитие экспорта продовольственных товаров и освоение новых товарных ниш, пригодных для контейнеризации и востребованных на монгольском рынке, будут положительно влиять на рост железнодорожных грузоперевозок при условии оптимизации тарифных условий.

Таким образом, вне всякого сомнения, реализация транспортно-логистических решений на территории Республики Бурятия крайне важна как на локальном уровне, так и для обеспечения российско-монгольской торговли в целом, и даже в свете продвижения международного транспортного коридора Россия - Монголия Китай на рынке грузоперевозок между Азией и Европой.

\section{Список литературы}

1. Авирмэд Даваасурэн. О состоянии российско-монгольских отношений. URL: $\quad$ https://russiancouncil.ru/blogs/owasia/o-sostoyanii-rossiyskomongolskikhotnosheniy/ (дата обращения: 16.04.2020).

2. Цыренова, Е. Б. Республика Бурятия во внешней политике Российской Федерации (монгольское направление) // Вестник Бурятского государственного университета. Педагогика. Филология. Философия. - 2011. - № 8. - С. 260-264.

3. Статистические данные Федеральной таможенной службы PФ. - URL: http://customs.ru/statistic (дата обращения: 16.04.2020).

4. Байкал-Daily : информ. агентство. - URL: https:/www.baikaldaily.ru/interview/360074/ (дата обращения: 20.09.2019).

5. Кокарев, К. А. Сотрудничество с Монголией - важное звено восточной политики России. - URL: https://riss.ru/analitycs/6819/ (дата обращения: 20.09.2019).

6. Соян, Ш. Ч. Анализ развития приграничных торгово-экономических отношений регионов Сибири с Монголией // Региональная экономика: теория и практика. - 2017. - Т. 15, вып. 4. - С. 632-643.

7. Россия и Монголия увеличат товарооборот за счет потенциала Дальнего Востока. - URL: https://minvr.ru/press-center/news/15146/ (дата обращения: 12.09.2020). 
8. Балдоржиев, Б. Б. Строительство транспортно-логистических, туристскорекреационных, инфраструктурных объектов, автомобильных дорог от МАПП Алтан-Булаг - Кяхта до г. Улан-Удэ // Экономический коридор Китай - Монголия Россия: дорожная карта / отв. ред. Б. В. Базаров, Ян Чэньхуа. - Улан-Удэ : Изд-во БНЦ СО РАН, 2017. - С. 171-174.

9. Хилийн боомтуудыг түр хааж, нэвтрэх хөдөлгөөнийг зогсоов. - URL: https://news.mn/r/2373199/ (дата обращения 15.11.2020). - Временно закрыты пограничные переходы, движение приостановлено.

\section{References}

1. Avirmed Davaasuren. O sostoyanii rossiisko-mongol'skikh otnoshenii [On the state of Russian-Mongolian relations]. Available at: https://russiancouncil.ru /blogs/owasia/o-sostoyanii-rossiyskomongolskikh-otnosheniy/ (accessed 16 April 2020).

2. Tsyrenova E. B. Respublika Buryatiya vo vneshnei politike Rossiiskoi Federatsii (mongol'skoe napravlenie) [Republic of Buryatia in the foreign policy of the Russian Federation (Mongolian direction)]. Vestnik Buryatskogo gosudarstvennogo universiteta. Pedagogika. Filologiya. Filosofiya, 2011, no. 8, pp. 260-264.

3. Statistical data of the Federal Customs Service of the Russian Federation. Available at: http://customs.ru/statistic (accessed 16 April 2020). (In Russian).

4. Baikal-Daily: inform. agency. Available at: https://www.baikal-daily.r u/inte rview/360074/ (accessed 20 September 2019). (In Russian).

5. Kokarev K. A. Sotrudnichestvo s Mongoliei - vazhnoe zveno vostochnoi politiki Rossii [Cooperation with Mongolia - an important link in Russia's eastern policy]. URL: https://riss.ru/analitycs/6819/ (accessed 20 September 2019).

6. Soyan Sh. Ch. Analiz razvitiya prigranichnykh torgovo-ekonomicheskikh otnoshenii regionov Sibiri s Mongoliei [Analysis of the development of border trade and economic relations between the regions of Siberia and Mongolia]. Regional'naya ekonomika: teoriya i praktika, 2017, vol. 15, iss. 4, pp. 632-643.

7. Russia and Mongolia will increase trade through the potential of the Far East. Available at: https://minvr.ru/press-center/news/15146/ (accessed 12 September 2020). (In Russian).

8. Baldorzhiev B. B. Stroitel'stvo transportno-logisticheskikh, turistskorekreatsionnykh, infrastrukturnykh ob"ektov, avtomobil'nykh dorog ot MAPP AltanBulag - Kyakhta do g. Ulan-Ude [Construction of transport and logistics, tourism and recreation, infrastructure facilities, highways from the Altan-Bulag - Kyakhta checkpoint to Ulan-Ude]. In: Bazarov B. V., Yang Chenhua (eds.) Ekonomicheskii koridor Kitai Mongoliya - Rossiya: dorozhnaya karta [Economic corridor China - Mongolia - Russia: road map]. Ulan-Ude: Publishing house of the BNTs SB RAS, 2017, pp. 171-174.

10. 9. Border crossings are temporarily closed, traffic is suspended. Available at: https://news.mn/r/2373199/ (accessed 15 November 2020). (In Mongolian). 